\title{
Peculiar aspects of qualified wrestlers' special workability and supreme nervous system functioning at special training stage of preparatory period
}

\author{
Sazonov V.V. \\ State Research Institute of Physical Culture and Sports
}

\begin{abstract}
Purpose:

to determine peculiar aspects of qualified wrestlers' special workability and supreme nervous system functioning in special training stage of preparatory period.

Material: $\quad 18$ qualified wrestlers if $17-20$ yrs age were tested. We used testing of special workability and psychophysiological testing.

Results: $\quad$ it was found that sportsmen's special workability was at rather high level. Though, recreation coefficient witnesses about some accumulation of fatigue. Besides, we registered reduction of central nervous system's functional potentials. It is proved by latent periods of simple and complex visual reactions (at low and below average levels). We found correlations between sportsmen's special endurance, level of complex visual-motor reaction and nervous processes' functional mobility. Besides, sportsmen with stronger nervous processes recreate quicker after standard loads.

Conclusions: it was found that alongside with high special workability sportsmen accumulate fatigue and have absence of recreation. It is proved by weakening of central nervous system's functional potentials. We supplemented the data about correlation between special workability and sportsmen's psycho-physiological condition. It was assumed that persistent influence on supreme nervous system will permit to sustain special workability at high level and prevent from over-training.

Keywords: fatigue, psycho-physiological indicators, special workability, recreation coefficient.
\end{abstract}

\section{Introduction}

Modern tendency of training process intensification in sport wrestling is connected with desire of international wrestling federation to raise show character of duels. For this purpose duration of competition duels and tournaments was shortened. Referee's practice was oriented on simulation wrestlers' activity together with increase of wrestling techniques' quantity [11, 26, 29].

In this connection, nowadays wrestling duel of qualified wrestlers has become a highly intensive kind of competition functioning [6, 17, 31]. By level of requirements and organism's potentials wrestling duel approaches to similar by duration kinds of cyclic sports competitions with intensive power component [18, 20, 21, 22].

Accordingly, it results in re-construction of training methodic and increase of requirements to wrestler's physical qualities $[6,16,25,30]$. It was shown that special endurance substantially influences on duel result $[2,28]$. Special attention is paid to special workability training in special-training stage of preparatory period. In this stage modeling of different competition situations with maximal physical loads is used for effective training. Such loads give the main training effect. At the same time application of such loads without proper control can result in over tension and over training [12, 13, 14, 15].

A number of scientists $[3,7,9,11]$ proved that wrestler's special workability is the main factor of influence on competition result. Though, in scientific literature there are no data about recreation processes in organism in special training stage of preparatory period,

(c) Sazonov V.V., 2017

doi:10.15561/18189172.2017.0108 especially after significant training loads, oriented on special workability in "advanced” micro-cycles.

Besides, it is necessary to consider conditions of duel in wrestling, situations, which change during duel. With it supreme nervous system's functioning plays very important role. It should also be noted that with possibility of over training and high special workability, psycho-physiological indicators can be the first markers of adaptation failure [8]. So, for obtaining more complete picture of wrestlers' fitness and organism's recreation special workability and psycho-physiological indicators shall be studied. A number of works is devoted to sportsmen's psycho-emotional and psycho-physiological states in different kinds of sports at different stages of training [8, 23, 24]. Though there are no data about correlation of wrestlers' special workability indicators and psycho-physiological indicators in special training stage of preparatory period. That is why we fulfilled correlation analysis between the mentioned indicators.

Hypothesis: it was assumed that in special training stage in qualified wrestlers weakening of supreme nervous system's functioning can be observed alongside with high special workability. Besides, we assumed that there are correlations between some special workability indicators and psycho-physiological indicators.

The purpose of the research is to determine peculiar aspects of qualified wrestlers' special workability and supreme nervous system functioning in special training stage of preparatory period.

\section{Material and methods}

Participants: 18 qualified wrestlers if $17-20$ yrs age were tested (free style wrestling; they were candidate 
masters of sports and masters of sport, among whom there were prize winners of Ukrainian championships). All participants gave written consent for participation in experiment.

Organization of the research: the research was fulfilled during "advanced" micro-cycle of special-training stage of preparatory period. Micro-cycle took 7 days and was directed at perfection of technical-tactic actions and training of sportsmen's special workability. Sportsmen's functional fitness was assessed by results of pedagogic tests: shuttle run $4 \times 9 \mathrm{~m}$, test for special endurance, test for recreation [4].

Psycho-physiological indicators were registered with the help of computer program "Psycho-diagnostic" [1]. Such program is designed for determination of supreme nervous system's individual characteristics, connected with visual information of different complexity processing by methodic of N.V. Makarenko and V.S. Lyzogub [10]. The testing was conducted in two modes: optimal and feedback communication. We registered simple and complex visual-motor reactions as well as nervous processes' functional mobility (NPFM) and nervous processes' strength (NPS).

The research was planned so that the day before testing was free from training loads. First we fulfilled psychophysiological diagnostic and then pedagogic testing.

Statistical analysis: statistical processing of the received results was fulfilled with the help of GraphPad Prism version 5.0 for Windows programs [19]. We determined the following: mean arithmetic $(\bar{x})$, standard errors (m). For finding of correlations between indicators we fulfilled correlation analysis: calculation of Spearman's rank correlation coefficients. Degree of correlation was determined by correlation coefficient $(r)$. Value $p \leq 0.05$ was regarded as statistically confident [5].

\section{Results}

From the received data (see table 1) we can see that the time of shuttle run distance covering corresponds to high values; special endurance coefficient (SEC) and quantity of repetitions in this test were above average; recreation coefficient (RC) was below average values, intrinsic to this specialization [4]. It witnesses about high quickness, dexterity and special workability. Though, recreational processes were slower after testing loads.

Wrestling is a kind of sport activity, in which situations constantly change and sportsman has to response to opponent's actions. That is why nervous system's functioning assessment is of great importance for determination of wrestler's fitness. For this purpose program "Psycho-diagnostic" was used [1]. As we can see in table 2 latent period of simple visual motor reaction (SVMR) is below average. Latent period of reaction to choice of one from three (RC 1-3) corresponds to low level. Latent period of reaction to choice of two from three (RC 2-3) also was at low level. The time of passing to minimal exposition, when finding functional mobility, corresponded to below average level [10]. Thus, we observed weakening of central nervous system's functional potentials. Alongside with referent values of

Table 1. Indicators of qualified wrestlers' pedagogic testing in special training stage of preparatory period $(\bar{x} \pm \mathrm{m}$; $\mathrm{n}=18$ )

\begin{tabular}{lll}
\hline Indicator & $\bar{x}$ & $\mathrm{~m}$ \\
\hline Shuttle run $4 \times 9 \mathrm{~m}, \mathrm{sec}$. & 8.26 & 0.05 \\
Coefficient of special endurance & 0.9211 & 0.009 \\
Quantity of repetitions in test for special endurance & 104.6 & 1.687 \\
Recreation coefficient & 0.8121 & 0.0111 \\
Quantity of "fireman's carry takedowns" in tests for RC & 23.17 & 0.5378 \\
Maximal heart beats rate (HBR) after test for recreation & 170.7 & 2.879 \\
\hline
\end{tabular}

Table 2. Psycho-physiological indicators of qualified wrestlers in special training stage of preparatory period $(\bar{x} \pm \mathrm{m}$; $\mathrm{n}=18$ )

\begin{tabular}{lll}
\hline Description of indicator & $\bar{x}$ & m \\
\hline SVMR, time of latent period, msec. & 306.1 & 8.604 \\
RC 1-3 time of latent period, msec. & 476.3 & 12.37 \\
RC 2-3 time of latent period, msec. & 538.9 & 10.14 \\
NPFM (feedback) time of latent period, msec. & 448.4 & 10.97 \\
NPFM (feedback) minimal time of signal's exposition, msec. & 424.4 & 18.33 \\
NPFM (feedback) total time of test fulfillment, sec. & 99.89 & 1.964 \\
NPFM (feedback) time of passing to minimal exposition, sec. & 74.89 & 4.547 \\
NPS (feedback) time of latent period, msec. & 405.3 & 5.994 \\
NPS (feedback) quantity of mistakes & 134.1 & 2.237 \\
NPS (feedback) minimal time of signal's exposition, msec. & 360.0 & 8.402 \\
NPS (feedback) time of passing to minimal exposition, sec. & 133.7 & 16.63 \\
\hline
\end{tabular}


Table 3. Correlations between pedagogic testing results and wrestlers' psycho-physiological indicators

\begin{tabular}{llll}
\hline Description of indicators & $\mathbf{r}$ & $\mathbf{p}$ \\
\hline $0.50<r>0.69$ & SVMR (latent period) and special endurance coefficient & 0.5126 & 0.0296 \\
& RC 1-3 (latent period) and quantity of repetitions in test for SEC & -0.5732 & 0.0129 \\
& NPFM (feedback, latent period) and quantity of repetitions in test for SEC & -0.5680 & 0.0139 \\
& NPFM , the forced rhythms (\% of mistakes at 5 ${ }^{\text {th }}$ stage) and SEC & -0.5438 & 0.0197 \\
& NPFM , the forced rhythms (\% of mistakes at 3 $3^{\text {rd }}$ stage) and shuttle run & -0.5748 & 0.0126 \\
& NPFM , the forced rhythms (\% of mistakes at 4 ${ }^{\text {th }}$ stage) and shuttle run & -0.5622 & 0.0152 \\
& NPFM , the forced rhythms (\% of mistakes at 5 ${ }^{\text {th }}$ stage) and shuttle run & -0.5006 & 0.0343 \\
$0.30<r>0.49$ & NPS (feedback) quantity of mistakes and recreation coefficient & 0.4823 & 0.0427 \\
& NPFM , the forced rhythms (\% of mistakes at 2 ${ }^{\text {nd }} \quad$ stage) and shuttle run & -0.4843 & 0.0417 \\
\hline
\end{tabular}

bio-chemical indicators it can be the marker of possible overtraining and adaptation failure [8, 23, 24].

The presented above indicators are only separate components, by which wrestlers' fitness can be characterized. That is why it would be purposeful to study correlation between in order to receive more objective information (see table 3).

The presence of average correlation between latent period of simple visual motor reaction and special endurance coefficient $(\mathrm{r}=0.51 ; \mathrm{p}=0.0296)$ illustrates that wrestlers with better simple reaction have lower special endurance.

In contrast to it we can observe feedback correlation between latent reaction of choice of one from three irritators and quantity of repetitions in test for special endurance $(\mathrm{r}=-0.57 ; \mathrm{p}=0.0129)$. Total quantity of repetitions in SEC test also is and indicator of special endurance level. That is why we can say that wrestler's special endurance depends on level of complex visual motor reaction.

Wrestler's special endurance also depends on functional mobility of nervous processes that is proved by reverse correlation between NPFM latent period and quantity of repetitions in SEC test $(\mathrm{r}=-0.57$; $\mathrm{p}=0.0139)$.

It is interesting that there is reverse correlation between time of covering shuttle run distance and percentage of mistakes in third, forth and fifth stages of NPFM determination with forced rhythm $(\mathrm{r}=-0.57 ; \mathrm{p}=0.0126$; $r=-0.56 ; p=0.0152 ; r=-0.50 ; p=0.0343$ accordingly). May be it is conditioned by prevalence of excitation processes over inhibition ones in wrestlers with higher quickness. Accordingly, the quantity of mistakes, made by such wrestlers in NPFM determination (with forced rhythm) is higher.

We found direct correlation between recreation coefficient and quantity of mistakes, made in determination of nervous processes' strength in feedback mode $(\mathrm{r}=0.48$; $\mathrm{p}=0.0427$ ). It is possible to assume that wrestlers with stronger nervous processes recreate after loads quicker. That is why optimization of recreation processes in qualified wrestlers' organisms at the account of supreme nervous system's functioning is logical and purposeful.

\section{Discussion}

It was found that in special training stage of preparatory period special workability of qualified wrestlers is rather high. It coincides with results of other researches [3, 7, 9]. Though the received by us data in test for recreation after standard work witness that recreation is not complete. It can be conditioned by great scope of special work in this training stage and fatigue's accumulation.

In wrestling, significant role in duel's efficiency is played by high special workability and supreme nervous system's functioning $[8,23,24]$. That is why we carried out psycho-physiological diagnostic with the help of program "Psycho-diagnostic". When determining individual characteristics of supreme nervous system in processing visual information of different complexity we found weakening of central nervous system's functional potentials. It is witnessed by the data of simple visual motor reaction to choice of one from three and two from three (they were at low level and below average) [10]. Such psycho-physiological indicators and high special workability can be markers of possible overtraining [8]. That is why we can state that in special training stage of preparatory period it is necessary to provide more careful observations over sportsmen's organisms from the side of coach, medical workers and scientists. For this purpose it is necessary to apply pedagogic, psycho-physiological and bio-chemical methods.

Correlation analysis showed that wrestler's special endurance depends on level of complex visual motor reaction and on nervous processes' mobility. It was found that wrestlers with stronger nervous processes recreate quicker after standard loads. That is why we can assume that persistent correction of wrestler's psychophysiological state by training and out-of-training means in this stage will facilitate prevention from over-fatigue and overtraining and sustain high special endurance.

\section{Conclusions:}

1. It has been found that in special training stage of qualified wrestlers' preparatory period, alongside with rather high special workability recreation coefficients witness about insufficient recreation and fatigue's accumulation.

2. The data of psycho-physiological; testing in this training stage show weakening of central nervous system's functional potentials that can point at possible overtraining. 
3. The data about wrestlers' special workability correlation with psycho-physiological state in special training stage of preparatory period have been supplemented. Assumption that persistent influence on supreme nervous functioning of wrestlers in this training

\section{Reference}

1. Kozina ZhL, Baribina LM, Korobiejnikov G V, Mishchenko DI, Cikunov OA, Kozin OV. Komp'iuterna programa «Psikhodiagnostika» [Computer program "Psychodiagnostic”], Ukraine patent 39679. 2011 Jun 10. (In Ukrainian)

2. Bleer AN, Igumenova LA. Kak povysit' sorevnovatel'nuiu nadezhnost' vysokokvalificirovannykh borcov [How to increase competition reliability of elite wrestlers]. Teoriia $i$ praktika fizicheskoj kul tury, 1999; 2: 53-55. (In Russian)

3. Bojko VF, Dan'ko GV. Fizicheskaia podgotovka borcov [Physical training of wrestlers]. Kiev: Olympic Literature; 2004. (In Russian)

4. Vil'na borot'ba [Free style wrestling], Kiev: ASBU; 2011. (In Ukrainian)

5. Eliseeva II, Iuzbashev MM. Obshchaia teoriia statistiki [General theory of statistic], Moscow: Finance and Statistics; 2004. (In Russian)

6. Kalmykov SV, Sagaleev AS, Dagbaev BV. Sorevnovatel'naia deiatel'nost' $v$ sportivnoj bor'be [Competition activity in sport wrestling], Ulan-Ude: Buryat State University Publ.; 2007. (In Russian)

7. Kolenkov OV. Modeliuvannia special'noi fizichnoi pidgotovlenosti borciv visokoi kvalifikacii v zakliuchnomu makrocikli na etapi maksimal'noi realizacii individual'nikh mozhlivostej. Kand. Diss. [Modeling of elite wrestlers' special physical fitness in final macro-cycle at stage of maximal realization of individual potentials. Cand. Diss.], Kiev; 2007. (In Ukrainian)

8. KorobejnikovGV,DudnikOK. Diagnostikapsikhoemocijnikh staniv u sportsmeniv [Diagnostic of sportsmen's psychoemotional states]. Sportivna medicina, 2006; 1: 33-36. (In Ukrainian)

9. Latishev SV. Special'na silova pidgotovka ta zasobi ii kontroliu u richnomu cikli trenuvannia kvalifikovanikh borciv. Kand. Diss. [Special power training and control over it in annual training cycle of qualified wrestlers. Cand. Diss.], Lviv; 2004. (In Ukrainian)

10.Makarenko MV. Metodika provedennia obstezhen' ta ocinki individual'nikh nejrodinamichnikh vlastivostej vishchoi nervovoi diial'nosti liudini [Methodic of examination and assessment of human supreme nervous functioning individual neuro-dynamic characteristics]. Fiziologichnij zhurnal, 1999; 4(45): 125-131. (In Ukrainian)

11.Malins'kij IJ. Individual'ni osoblivosti funkcional'noi pidgotovlenosti kvalifikovanikh borciv vil'nogo stiliu. Kand. Diss. [Individual characteristics of free style qualified wrestlers' functional fitness. Cand. Diss.]. Kiev; 2002. (In Ukrainian)

12.Platonov VN. Periodizaciia sportivnoj trenirovki [Periodizing of sport training], Kiev: Olympic Literature; 2013. (In Russian)

13.Platonov VN. Sistema podgotovki sportsmenov v olimpijskom sporte [System of sportsmen's training in Olympic sports]. Kiev: Olympic Literature; 2013. (In Russian)

14.Ament W, Verkerke GJ. Exercise and fatigue. Sports Med. 2009; 39 (5): 389-422.

15.Beneke R, Böning D. The limits of human performance. Essays Biochem. 2008; 44: 11-25. stage permits to sustain high special workability and prevent from overtraining, has been made.

\section{Conflict of interests}

The author declares that there is no conflict of interests.

16.Demirkan E, Koz M, Kutlu M, Favre M. Comparison of physical and physiological profiles in elite and amateur young wrestlers. J Strength Cond Res. 2015; 29 (7): 18761883.

17.Horswill A, Scott JR, Galea P. Comparison of maximum aerobic power, maximum anaerobic power, and skinfold thickness of elite and nonelite junior wrestlers. Int. J. Sports Med. 1989; 10(3): 165-168.

18.Horswill CA. Applied physiology of amateur wrestling. Sports Med. 1992; 14 (2): 114-143.

19.Compare GraphPad's four programs. [homepage on the Internet]. 2016 [cited 2016 Dec 10]. Available from: http:// www.graphpad.com/scientific-software

20.Hubner-Wozniak I, Kosmol A, Blachnio D. Anaerobic capacity of upper and lower limbs muscles in combat sports contestants. Journal of Combat Sports and Martial. 2011; 2: 91-94.

21.Chino K, Saito Y, Matsumoto S, Ikeda T, Yanagawa Y. Investigation of exercise intensity during a freestyle wrestling match. J Sports Med Phys Fitness. 2015; 55 (4): 290-296.

22.Karnincić H. Glucose dynamics can evaluate state of anaerobic fitness in wrestling?! Coll Antropol. 2013; 37: 101-106.

23.Korobeynikov G, Korobeynikova L, Mazmanian K, Jagiello W. Diagnostics of psychophysiological states and motivation in elite athletes. Bratislava Medical Journal. 2011; 112 (11): 637-644.

24.Korobeynikov G, Mazmanian K, Korobeynikova L, Jagiello W. Psychophysiological states and motivation in elite judokas. Archives of Budo. 2010; 6 (3): 129-136.

25.Kutlu M, Demirkan E, Özbek ME. Assessments of world and national level wrestling teams at a pre world championship competition: hydration, body composition and body mass alterations. J Sports Med Phys Fitness. 2015; 55 (4): 305312.

26.Noakes TD. Physiological models to understand exercise fatigue and the adaptations that predict or enhance athletic performance. Scand J Med Sci Sports. 2000; 10 (3): 123-145.

27.Demirkan E, Kutlu M, Koz M, Özal M, Favre M. Physical fitness differences between freestyle and Greco-Roman junior wrestlers. Journal of Human Kinetics. 2014; 41: 245251.

28.García-Pallarés J, López-Gullón JM, Muriel X, Díaz A, Izquierdo M. Physical fitness factors to predict male Olympic wrestling performance. Eur J Appl Physiol. 2011; 111 (8): 1747-1758.

29.Barbas I, Fatouros IG, Douroudos II, Chatzinikolaou A, Michailidis Y, Draganidis D, Jamurtas AZ, Nikolaidis MG, Parotsidis C, Theodorou AA, Katrabasas I, Margonis K, Papassotiriou I, Taxildaris K. Physiological and performance adaptations of elite Greco-Roman wrestlers during a one-day tournament. Eur. J. Appl. Physiol. 2011; 111(7): 1421-1436.

30.Farzad B, Gharakhanlou R, Agha-Alinejad H, Curby DG, Bayati M, Bahraminejad M, Mäestu J. Physiological and performance changes from the addition of a sprint interval program to wrestling training. J Strength Cond Res. 2011; 25 (9): 2392-2399.

31. Yavuz HU, Turnagol H, Demirel AH. Pre-exercise arginine supplementation increases time to exhaustion in elite male wrestlers. Biol Sport. 2014; 31: 187-191. 


\section{Information about the author:}

Sazonov V.V.; http://orcid.org/0000-0001-8497-8476; sazonov_m@ukr.net; State Research Institute of Physical Culture and Sports; st. Physical Education, 1, Bldg. 2, m. Kyiv - 150, 03680, Ukraine.

Cite this article as: Sazonov V.V.Peculiar aspects of qualified wrestlers' special workability and supreme nervous system functioning at special training stage of preparatory period. Pedagogics, psychology, medical-biological problems of physical training and sports, 2017;1:46-50. doi:10.15561/18189172.2017.0108

The electronic version of this article is the complete one and can be found online at: http://www.sportpedagogy.org.ua/index.php/PPS/issue/archive

This is an Open Access article distributed under the terms of the Creative Commons Attribution License, which permits unrestricted use, distribution, and reproduction in any medium, provided the original work is properly cited (http://creativecommons.org/licenses/by/4.0/deed.en).

Received: 06.10.2016

Accepted: 18.12.2017; Published: 24.01.2017 